\title{
Araştırma Yöntemleri Bilgisinin Önemi: Turizm Alanına Yönelik Bir Gömülü Teori Çalışması
}

\author{
The Knowledge of Research Methods: A Study of Grounded Theory in Tourism
}

\author{
Serhat Adem SOP*, Metin KOZAK** \\ *(Sorumlu Yazar) Dr. Öğr. Üyesi, Burdur Mehmet Akif Ersoy Üniversitesi, Turizm İşletmeciliği ve Otelcilik Yüksekokulu, 15030, Burdur. \\ E-posta: serhatademsop@gmail.com \\ ORCID: 0000-0001-9096-9496 \\ ** Prof. Dr., Metin Kozak, Kadir Has Üniversitesi, Iletişim Fakültesi, Reklamcılık Bölümü, Cibali, 34083, Fatih-İstanbul. \\ E-posta: metin.kozak@khas.edu.tr \\ ORCID: 0000-0002-9866-7529
}

MAKALE BILGILERI

Makale işlem bilgileri:

Gönderilme tarihi: 23 Haziran 2020

Düzeltme: 14 Ekim 2020

Düzeltme: 14 Ocak 2021

Kabul: 19 Ocak 2021

Anahtar sözcükler: Turizm araştırmaları, Paradigma değişimi, Geleneksel yaklaşım, Evrensel yaklaşım, Araştırma yöntemleri, Gömülü teori.

\section{ARTICLE INFO}

Article history:

Submitted: 23 June 2020

Resubmitted: 14 October 2020

Resubmitted: 14 January 2021

Accepted: 19 January 2021

Key words: Tourism research, Paradigm shift, Traditional approach, Universal approach, Research Methods, Grounded theory.

\begin{abstract}
$\ddot{O Z Z}$
Turizm akademisinde araştırma yöntemleri bilgisine atfedilen önemin belirlenmesi ve yöntem bilgisinin ortaya çıaracağı etkilerin tartıșıması amacıyla yürütülen bu çalıșmada nitel araștırma paradigması uygulanmıştır. Hazırlanan 16 soruluk çevrimiçi soru formu kolayda örnekleme tekniği ile belirlenmiş olan bireyler ile e-posta ve sosyal medya üzerinden özel mesaj gönderilerek paylaşılmış, 39 katılımcıdan ulaşılan veriler gömülü teori yaklașımıyla analiz edilmiștir. Bu bağlamda; turizm araștırmalarındaki yayğın yöntemsel paradigmada değişimine intiyaç duyulduğu, nicel veya nitel yöntemlere odaklanmak yerine problem-yöntem uyumuna dikkat edilmesi gerektiği, nitelikli bir araştırmacı olabilmek için yöntem bilgisinin son derece önemli bulunduğu sonucuna ulaşılmıştır. Araştırma yöntemleri bilgisinin doğrudan ve dolaylı etkileri ise "geleneksel yaklaşım" ve "evrensel yaklașım" olarak adlandırılan iki yaklașım çerçevesinde yorumlanmıștır. Bu yönüyle mevcut çalıșma, turizm araştırmacılarına evrensel yaklaşımı bir vizyon olarak sunmakta ve "araştırma yöntemleri bilgisi neden gereklidir?" sorusunu kapsamlı biçimde yanıtlayarak alan yazındaki önemli bir boşluğu doldurmaktadır.
\end{abstract}

\section{GiRiş}

Turizm, 1970'li yılların başlarında sosyal bilimciler tarafından keşfedilmiş ve ilerleyen dönemlerde sistematik biçimde devam eden araştırmalar sayesinde akademik anlamda bir eğitim ve araştırma alanı olarak kendisini kabul ettirmeye başlamıştır (Dann, Nash ve Pierce 1988). Ancak, turizmin bilimsel bir olgu olduğuna dair ilk ipuçları daha eskiye dayanmaktadır. Birinci Dünya Savaşı ve İkinci Dünya Savaşı'nın getirdiği ekonomik yıkımın aşılması için çalışan Glücksmann, Hunziker, Krapf ve Kaspar gibi Alman okulunu temsil eden ekonomistlerin turizmin ekonomik etkilerini sorgulamaya başladıkları görülmektedir. 1950'li yıllardan sonra sosyoloji ve coğrafya 
alanlarındaki akademisyenler turizmi konu alan çalışmalar yürütmeye başlarken, 1960'ı yıllardan itibaren ise önceki ylllara ek olarak, uluslararasılaşmanın başladığı daha geniş bir coğrafyada psikoloji, antropoloji ve işletmecilik alanlarında turizm araştırmalarının yürütüldüğü bilinmektedir (Kozak ve Kozak 2016). Günümüzde ise turizm alanını temsil eden akademisyen ve araştırmacıların oranı oldukça yüksektir.

Bu tarihsel süreç, doğuşundan itibaren turizmin hem disiplinlerarası bir araştırma alanı olduğunu hem de ekonomik, sosyolojik, psikolojik, antropolojik ve coğrafi bir olgu olduğunu açıça göstermektedir (Rangus ve Brumen 2016). Bu nedenle, turizm araştırmalarının hem teorik açıdan bilime katkı sağlaması hem de sektörün sorunlarını giderici ve toplum refahını artırıcı bir rol üstlenmesi beklenmektedir. Nitekim, turizm alanındaki uluslararası nitelikli akademik dergiler yayımlayacakları makalelerde teorik ve uygulamaya dönük katkıları bu gerekçeyle aramaktadır. Söz konusu beklentilerin karşılanıp karşılanmaması ise turizm alanında yayın yapan araştırmacıların sorumluluğundadır. Bu nedenle, turizm araştırmacılarının tasarım ve yöntem bilgisinin mümkün olduğunca iyi olması gerekmektedir.

Erdoğan (2001), çoğu sosyal bilim araştırmacısı gibi turizm araştırmacılarının da tasarım ve yöntem bilgisi konusundaki eksikliğine dikkat çekmektedir. Bu kapsamda Kock (2019), nitelikli turizm dergilerinde yayımlanan ölçek geliştirme çalışmalarını geçerlik ve güvenirlik sorunları açısından eleştirmektedir. Çıvak ve Sezerel (2018) ise Türkiye'de faaliyet gösteren turizm dergilerinde çoğunlukla pozitivist paradigmanın ve nicel yöntemlerin uyguladığını ortaya koymaktadır. Bu durum, Türk turizm araştırmacılarının Sosyal Bilimler Atıf Endeksi [Social Sciences Citation Index - SSCI] tarafından taranan dergilerdeki yayınlarında da açıkça gözlemlenmektedir (Acar ve Gül-Yılmaz 2019). Uzun zamandır turizm araştırmalarında karşılaşılan genel durum, son yıllarda nitel veya karma araştırma tasarımıyla yürütülen araştırma sayısının artmasına karşın, sıklıkla anket tekniğinden yararlanılarak verilerin toplandığ $\breve{v}$ ve bu verilerin regresyon analizi veya yapısal eşitlik modellemesi gibi çok değişkenli istatistiksel analizler yoluyla çözümlendiği yönündedir.

Tüm bu gözlemlerden hareketle tasarlanan bu çalışmada, turizm alanındaki araştırmacılar için yöntem bilgisinin ne kadar ve neden önemli olduğu sorusu yanıtlanarak araştırma yöntemleri bilgisinin doğrudan ve dolaylı etkilerinin neler olabileceği tartışılmaktadır. Turizm alan yazını incelendiğinde; turizm araştırmalarının nasıl geliştiği (Faulkner ve Goeldner 1998), diğer disiplinlerden ne kadar atıf aldığ 1 (Wardle ve Buckley 2014), yapısal eşitlik modellemesinin neden ve nasıl kullanıldığ (Nunkoo, Ramkissoon ve Gursoy 2013), hangi araştırma yöntemlerinin daha çok tercih edildiği (Nunkoo, Thelwall, Ladsawut ve Goolaup 2020) gibi soruları yanitlayan çalışmalara rastlanmaktadır. Buna karşın, turizm araştırmacılarının yöntem konusuna atfettiği önemi ve araştırma yöntemleri bilgisinin doğuracağı bütüncül etkileri tartışan bir çalışmaya ulusal ya da uluslararası düzeyde rastlanmamaktadır. Bu hususta, çalışmanın turizm araştırmacılarına bir vizyon sunacağ önemli boşluğu dolduracağı düşünülmektedir.

\section{ALANYAZIN TARAMASI}

Turizm araştırmalarının geçmişine bakıldığında, ilk dönemlerde daha çok derleme/kavramsal niteliğindeki makale çalışmaları üzerine yoğunlaşıldığı görülmektedir. Amerika ve İngiltere odaklı uluslararası yayınevleri tarafından yayımlanan dergilerin de piyasaya girmesiyle birlikte, 1970'li yıllardan itibaren araştırma odaklı makalelere yer verilmeye başlanmıştır. Bu tür bir yoğunluğun 1990'lı yıllarla birlikte artışa geçtiği ve bu yüzyılın başından itibaren en üst düzeye ulaştığı gözlemlenmektedir. Günümüzde, derleme/kavramsal makale yayımlayan turizm dergisi neredeyse kalmamış durumdadır. Aradan geçen elli yıllık dönem sonucunda turizm araştırmaları, akademik anlamda nitelik ve nicelik açısından olağanüstü bir gelişim göstererek sosyal bilimlerin diğer disiplinleri ile paralel hareket edebilme şansını yakalamıştır. Böylesine hızlı ve dinamik bir gelişme araştırma yöntemlerinin önemine de işaret etmektedir. 
Nitekim, Acar ve Gül-Yılmaz (2019) tarafından yürütülen bir bibliyometri çalışması, SSCI kapsamında taranan turizm dergilerinde Türkiye özelindeki yayın sayısının her geçen gün arttığını göstermektedir. Bu artışın 2016 yılında hızlandığı, yayınların önemli bir bölümünün ise iki kurum ve on akademisyen tarafından üretildiği belirtilmektedir. Araştırmada dikkat çeken diğer bir husus, bu çalışmaların büyük bir kısmında (\%80) nicel araştırma yöntemlerinin tercih edilmesidir (Acar ve Gül-Yılmaz 2019). Çin'de yürütülen benzer bir araştırma ise 1979-2015 yılları arasında yayımlanan makalelerin yaklaşık yarisında nicel ve yarıdan az bir kisminda da nitel araştırma yöntemlerinin uygulandığını göstermektedir (Bao, Chen ve Jin 2018).

Turizm alanının önde gelen akademik dergilerinden olan Annals of Tourism Research, 2006 yılından bu yana belirgin biçimde nitel araştırmaları yayımlamaktadır (Nunkoo, Hall ve Ladsawut 2017). Dolayısıyla, Türk turizm araştırmacılarının pozitivist paradigmaya bu denli bağlılı$\breve{g} 1$ ve nicel araştırma tutkusu çeşitli dönemlerde eleştirilmektedir (Akış-Roney 2011; Yüksel 2019). Çünkü akademik araştırmalardaki amaç incelenen konuyu özümsemek ve açıklamak olduğu için pozitivist paradigmanın getirdiği nicel yaklaşımların yanında diğer bilimsel paradigmaların da uygulanması gereklidir (Akış-Roney 2011). Bu yanlılık, Türk turizm araştırmacılarının betimsel düzeyi aşamayan ve uluslararası turizme katkı sağlayamayan yayınlar çıkarmasına neden olmaktadır (Yüksel 2019).

Acar ve Gül-Yilmaz (2019), SSCI'da taranan turizm dergilerinde en çok yayın yapan Türk akademisyenlerin bir listesini sunmaktadır. Bu listede yer alanların bir bölümü araştırma yöntemleri üzerine kitaplar ve yazılar yazan, hatta araştırma yöntemleri ve nitelikli yayın yapma konusunda seminerler veren isimlerdir. Bu da yöntem bilgisi iyi düzeyde olan turizm akademisyenlerinin nitelikli dergilerde daha fazla yayın yapabileceğini kanitlayan bir bulgudur. Elbette, üst düzey dergilerde yayın yapmak isteyen araştırmacıların yöntemsel açıdan kendilerini geliştirmeleri son derece önemli bir husustur (Brennan 2019). Bununla birlikte, araştırmacının yöntemsel yeterliği, özgün araştırma konularını bulmasına ve yeni yöntemsel yaklaşımları uygulayabilmesine dahi etki etmektedir (Rodriguez-Sanchez, Makkonen ve Williams 2019).

Araştırma yöntemleri bilgisinin yetersizliği ise problemin belirlenmesinden bulguların yorumlanmasına kadar süren bilimsel araştırma safhalarında çok çeşitli hataların ortaya çıkmasına sebep olmaktadır (Yücel-Toy ve Güneri-Tosunoğlu 2007). Yetersiz yöntem bilgisi, araştırmacının çalışma motivasyonunu da olumsuz etkileyebilmektedir. Kamu üniversitelerinin turizm bölümlerinde çalışan her üç araştırma görevlisinden birisi bilimsel araştırmada kullanılacak yöntem ve teknikleri belirlemede zorlandığ 1 için bu sorun ile karşılaşmaktadır (Sop 2017). Araştırma tasarı$\mathrm{m}$, veri toplama ve analizi konularında yaşanan bu sorunlar, ortaya çıkarılan çalışmanın ulusal ya da uluslararası düzeydeki nitelikli dergilerde yayımlanmasını da güçleştirmektedir.

Anlaşılacağı üzere yöntem bilgisi; hatasız, nitelikli ve alana teorik katkı sağlayabilen çalışmaların üretilmesinde oldukça etkilidir (Yücel-Toy ve Güneri-Tosunoğlu 2007; Türkdoğan 1995). Ancak, bilimsel bir araştırma sadece teorik değil, sektörel yani uygulamaya dönük katkı da sağlayabilmelidir (Jones ve Phillips 2003). Günümüzde sektör yöneticilerinin ihtiyaç duydukları bilgiyi akademik dergiler veya konferanslardan ziyade işletme ve kişisel bağlantılarından edinmeleri (Vong 2017), turizm araştırmacılarının kendilerini sorgulamasını gerektirmektedir. Bu problemin temelini inceleyen Khan (2019), yürütülen araştırmaların otelcilik sektöründe zaten bilinen bulgulara ulaşması nedeniyle uygulamacılara gerekli bilgiyi sağlayamadığı, öğrenciler ya da kolay ulaşılabilir örneklemler üzerine yapılan anket araştırmalarıyla sektörün ihtiyaçlarından uzaklaşıldığı, sektör ve akademinin bir akademik çalışmada değerli gördükleri noktaların uyuşmadığ 1 gibi önemli hususları ortaya koymaktadır. Bu bağlamda, yöntemsel konuların akademi ve sektör arasındaki mesafeyi etkilediği de ifade edilebilmektedir.

Diğer yandan, son yıllarda nitel veya karma araştırma tasarımıyla yürütülen araştırmaların arttığı da görülmektedir. Ancak, söz konusu geleneksel araştırma yöntem ve tekniklerinin eleş- 
Tablo 1. Çevrimiçi Soru Formunda Yer Alan Sorular

\begin{tabular}{|c|c|}
\hline Soru 1: & $\begin{array}{l}\text { Alanınızın araştırma yöntemleri açısından geldiği noktayı nasıl değerlendiriyorsunuz? Yeni } \\
\text { yöntem ve tekniklere ihtiyaç duyulmakta mıdır? Neden? }\end{array}$ \\
\hline Soru 2: & $\begin{array}{l}\text { Alanınızın bilimsel gelişimi için araştırma yöntemleri bilgisinin ne düzeyde önemli olduğunu } \\
\text { düşünüyorsunuz? Neden? }\end{array}$ \\
\hline Soru 3: & $\begin{array}{l}\text { Alanınızın bilimsel gelişiminde nitel, nicel veya karma yöntemin mi daha gerekli/etkili olduğunu } \\
\text { düşünüyorsunuz? Neden? }\end{array}$ \\
\hline Soru 4: & $\begin{array}{l}\text { Araştırma yöntemleri bilgisine sahip olmayı kişisel/akademik gelişiminiz için gerekli görüyor } \\
\text { musunuz? Neden? }\end{array}$ \\
\hline Soru 5: & Araştırma yöntemleri konusunda kendinizi yeterli görüyor musunuz? Neden? \\
\hline Soru 6: & $\begin{array}{l}\text { Bu zamana kadarki çalışmalarınızda ağılıklı olarak hangi araştırma yönteminden ve hangi } \\
\text { analizlerden faydalandınız? }\end{array}$ \\
\hline Soru 7: & Araştırmalarınızda veri analizini kendiniz mi yaparsınız, yoksa destek mi alırsınız? Neden? \\
\hline Soru 8: & $\begin{array}{l}\text { Alanınızda lisansüstü düzeyde verilen araştırma yöntemleri derslerini yeterli/verimli buluyor } \\
\text { musunuz? Neden? }\end{array}$ \\
\hline \multicolumn{2}{|c|}{ Tanımlayıcı Sorular (9-16) } \\
\hline Soru 9: & Hangi bilim dalında / disiplin alanında çalışıyorsunuz? \\
\hline Soru 10: & Kaç adet "araştırma makalesi" yayınınız bulunmaktadır? \\
\hline Soru 11: & Kaç adet "derleme makalesi" yayınınız bulunmaktadır? \\
\hline Soru 12: & Kaç adet "SSCl/SCl/SCl Expanded" makaleniz bulunmaktadır? \\
\hline Soru 13: & $\begin{array}{l}\text { Kaç yıldır akademisyen olarak çalışıyorsunuz? Unvanınız nedir? (Yüksek Lisans ya da Doktora } \\
\text { öğrencisiyseniz lütfen belirtiniz). }\end{array}$ \\
\hline Soru 14: & Hangi üniversitede çalışıyorsunuz? \\
\hline Soru 15: & $\begin{array}{l}\text { Ülkemizde herhangi bir araştırma yöntemleri kursuna/seminerine katıldınız mı? Evet ise lütfen } \\
\text { nerede katıldığınızı, ismini ve süresini belirtiniz. }\end{array}$ \\
\hline Soru 16: & $\begin{array}{l}\text { Başka bir ülkede herhangi bir araştırma yöntemleri kursuna/seminerine katıldınız mı? Evet ise } \\
\text { lütfen nerede katıldığınızı, ismini ve süresini belirtiniz. }\end{array}$ \\
\hline
\end{tabular}


tirilmeye başlandiğ 1 (Laws ve Scott 2015; Scott, Zhang, Le ve Moyle 2019); cilt iletkenliği, yüz elektromiyografisi ve göz izleme gibi yeni veri toplama ve çözümleme tekniklerinin turizm araştırmalarında daha sık kullanıldığı gözlemlenmektedir (Lanke ve Nath 2020; Scott vd. 2019). $\mathrm{Bu}$ durum, bazı araştırmacıların yeni yöntemlere yöneldiğini, disiplinlerarası etkileşimin arttığını ve alanda yöntemsel bir paradigma değişiminin ortaya çıktığını kanıtlamaktadır. Söz konusu değişimin turizm alanında nasıl bir dönüşümü tetiklediği ise henüz bilinmemekledir. Ancak, önümüzdeki yıllarda, büyük veri, yapay zekâ, sanal ortamda deney çalışmaları gibi teknolojideki ilerlemelerinin de doğrudan etkisiyle, veri toplama ve analizi tekniklerinde önemli yapısal değişikliklerin olacağını söylemek mümkündür.

Yukarıda irdelenen tüm konular "araştırma yöntemleri bilgisi neden gereklidir?" sorusunun önemini göstermektedir. Bu sorunun bütüncül olarak yanıtlanabilmesi için birtakım alt soruların da sorulması gereklidir. Örneğin; “yöntem bilgisi bireysel açıdan ne gibi kazanımlar sağlayabilir? Turizm alanının yöntemsel açıdan mevcut konumu nasıl değiştirilebilir? Bu anlamda bir paradigma kayması mümkün müdür?". Çalışmanın bundan sonraki bölümünde, yöntem bilgisinin araştırmacılar ve turizm alanı üzerindeki etkilerini konu alan çeşitli sorulara yanıtlar aranmaktadır.

\section{YÖNTEM}

Bu çalışmada nitel araştırma paradigması benimsenmiş ve veri toplama aracı olarak yapılandırılmış çevrimiçi soru formu kullanılmıştır. İki bölümden oluşan soru formunun birinci bölümünde katılımcıların araştırma yöntemleri konusundaki yetkinlikleri, turizm alanının bilimsel gelişiminde yöntem bilgisinin rolü ve lisansüstü turizm eğitiminde verilen araştırma yöntemleri derslerinin niteliği hakkındaki görüşlerini belirlemeye yönelik sekiz soruya yer verilmiştir. İkinci bölümde ise, katılımcıları betimlemek üzere sekiz soru yöneltilmiştir. Formdaki tüm sorular, alan yazındaki tartışmalardan hareketle araştırmacılar tarafından hazırlanmış, üç akademisyen tarafından gözden geçirilmiş ve iyileştirmeler yapılarak son halini almıştır (Tablo 1).

Araştırmanın evreni, Türkiye'nin farklı üniversitelerinde görev yapan turizm akademisyenleri ve lisansüstü turizm öğrencileri ile sınırlandırılmıştır. Lisansüstü öğrencilerin evrene dâhil edilmesinin nedeni, araştırma yöntemleri konusunda aldıkları eğitimi ve okudukları bilimsel çalışmalardaki yöntemsel hususları (hatalar, yenilikler, baskın paradigma gibi) değerlendirebilecek düzeyde bireyler olmalarıdır. Bu kapsamda henüz araştırma yöntemleri dersi almamış öğrenciler evrenin dışında bırakılmıştır. Hazırlanan çevrimiçi soru formu kolayda örnekleme tekniği uygulanarak mümkün olduğunca fazla kişiye e-posta ve sosyal medya üzerinden özel mesaj yoluyla paylaşılmıştır. Soru formu, $14 \mathrm{Kasım}$ 2019-3 Ocak 2020 tarihleri arasında 39 katılımcı tarafından yazılı olarak yanıtlanmış, elde edilen veriler ise gömülü teori yaklaşımıyla analiz edilmiştir. Daha önce tartışılmamış bir konu hakkındaki bilinmeyenleri teorik bir zeminde bütüncül olarak ortaya çıkarmayı amaçlayan özgün bir araştırma olması nedeniyle bu çalışmada gömülü teori yaklaşımı benimsenmiştir. Bu doğrultuda araştırmanın nitel verileri, Corbin ve Staruss (1990) tarafından gömülü teori yaklaşımıyla veri analizinde kullanılması önerilen üç aşamalı kodlama tekniğiyle çözümlenmiştir (açık kodlama [open coding], eksenel kodlama [axial coding] ve seçici kodlama [selective coding]). İlk olarak, katılımcların yanıtları incelenmiş ve öne çıkan kavramlar belirlenerek katılımcılar arasındaki görüş benzerlikleri/farklılıkları tespit edilmiştir [açık kodlama]. Buradan ulaşılan kavram ve görüşlerden hareketle alt kategoriler oluşturulmuştur [eksenel kodlama]. Son olarak, tüm alt kategorileri kapsayacak temel kategoriler ileri sürülerek incelenen olgu hakkında nihai çıkarım yapılmıştır [seçici kodlama]. İkinci ve altıncı soruda ise katılımcılardan sadece önem derecesi ve bir tercih belirtmeleri istendiği için üç aşamalı kodlama tekniği uygulanmamıştır. Her soru bazında ulaşılan bulgulardan hareketle araştırmanın temel problemi olan "araştırma yöntemleri bilgisi neden gereklidir?" sorusu yanıtlanmaya çalışılmıştır. 


\section{BULGULAR}

Veri analizinden önce katılımcıların soru formundaki betimleyici sorulara verdiği yanıtlar incelenmiş ve genel özellikleri belirlenmiştir. Buna göre, araştırmaya 25 üniversiteden turizm anabilim dalında çalışma yapan veya eğitim alan 39 kişi katılmıştır. Katılımcıların unvana göre dağılımı; Dr. Öğr. Üyesi (9), Doç. Dr. (7), yüksek lisans öğrencisi (6), Prof. Dr. (3), Öğr. Gör. Dr. (3), doktora öğrencisi (5), Arş. Gör. Dr. (1) ve unvanını belirtmeyenler (5) şeklindedir. Herhangi bir akademik kadroda görevli olan 30 katılımcının akademideki görev süreleri iki ila 26 yıl arasında değişmektedir.

Katılımcıların araştırma makalesi türünden yayın sayıları incelendiğinde, henüz yayını bulunmayan altı yüksek lisans öğrencisi dışındaki 33 katılımciya ait yayın ortalamasinın 12 olduğu görülmektedir (en az bir, en fazla 60, toplam 393). Ayrıca, 18 katılımcinın derleme makalesi türünden (en az bir, en fazla 22, toplam 78 yayın), 15 katılımcının ise SSCI/SCI/SCI Expanded endekslerinde taranan (en az bir, en fazla beş, toplam 25) makale çalışmaları bulunmaktadır. Katılımcılardan sadece ikisi bir kez yurtdışında araştırma yöntemleri kursuna katıldığını; 20'siise, Türkiye'de çeşitli araştırma yöntemleri seminerlerine katıldığını belirtmektedir.

Tablo 2'de araştırmanın problemine ilişkin bulgular yer almaktadır. Katılımcıların, turizm alanının araştırma yöntemleri açısından geldiği noktayı nasıl değerlendirdikleri sorusuna verdiği yanıtlardan hareketle açık, eksenel ve seçici kodlama gerçekleştirilmiştir. Ancak, 39 katılımcinın yanitları tam olarak metne aktarılamayacağı için açık kodlamaya ilişkin bulgular tabloya yansıtılmamıştır (bu yaklaşım çalışmanın sonraki bölümlerinde de uygulanmıştır). Eksenel kodlama bulguları, turizm alanında kullanılan yöntem ve tekniklerde yenilik ihtiyacının olduğunu göstermektedir. Katılımcıların görüşleri; geleneksel araştırma yöntemlerinin yetersiz kaldığı, karma ve nitel araştırma paradigmalarının daha çok benimsenmesi gerektiği, güncel tekniklerin ve deneysel tasarımın uygulandığı araştırmaların arttırılması ve disiplinlerarası etkileşimin güçlendirilmesi yönündedir. Ayrıca, tekrar eden araştır- malar nedeniyle moda haline getirilen yöntemsel tekniklerin çeşitlendirilmesi, post-modern bilim paradigması izlenerek yöntemsel çeşitliliğin arttırılması ve sektöre katkı verebilecek nitelikte araştırmalar yapmanın gerekliliği yönünde görüşler bulunmaktadır. Buradan hareketle, turizm alanında geleneksel yöntemsel yaklaşımlara karşı ciddi eleştirilerin bulunduğu ve bir paradigma değişimine ihtiyaç duyulduğu ileri sürülebilmektedir [Soru 1].

Araştırma yöntemleri bilgisinin alanın bilimsel gelişimindeki etkisini değerlendiren yanıtlar ise içerik analiziyle çözümlenmiş ve yöntem bilgisinin turizm alanının bilimsel gelişiminde çok önemli bir faktör olarak yorumlandığ $\breve{1}$ sonucuna ulaşılmıştır [Soru 2]. Alanın gelişiminde araştırma yöntemlerinin “olmazsa olmaz!" şeklinde ele alınmasına ek olarak, hangi yöntemin daha etkili olabileceği konusundaki soruya verilen yantlar ise karma yönteme işaret etmektedir. Katılımcıların bazıları ise nicel veya nitel araştırma yöntemlerini savunmaktadır. Ancak, genel olarak araştırma problemine uygun yöntemin tercih edilmesi gerektiği belirtilmektedir. Bu çerçevede, karma araştırma yöntemlerinin alanın bilimsel gelişimi için daha etkili bulunduğu ve problem-yöntem uyumunun son derece önemli görüldüğü anlaşılmıştır [Soru 3].

Yöntem bilgisi, akademik gelişim için gereklikten ziyade bir zorunluluk olarak görülmekte ve kaliteli çalışma yapabilme becerisini edinmek, alanda uzmanlaşmak, hatta popüler bir akademisyen olabilmek için temel ölçüt olarak yorumlamaktadır. Bazı katılımcılar da çalışma yaparken başkalarından destek alma ihtiyacını ortadan kaldırabilmek için yöntem bilgisinin önemli olduğuna inanmaktadır. Bu durumda, yöntem bilgisinin nitelikli araştırmacı olabilme ile özdeşleştirildiği söylenebilmektedir [Soru 4].

Katılımcıların önemli bir bölümü kendisini araştırma yöntemleri konusunda yetersiz bulmaktadır. Katılımcıların kendilerini yetersiz hissetmelerinin nedenleri ise eğitim sorunları ve tecrübe eksikliği olarak yorumlanmaktadır. Tecrübe eksikliği sorunu özellikle akademiye yeni katıld1ğını belirten bireylerde gözlemlenen bir durumdur. Bazı katılımcılar da araştırma yöntemleri 
Tablo 2. Araştırma Sorularına İlişkin Bulgular

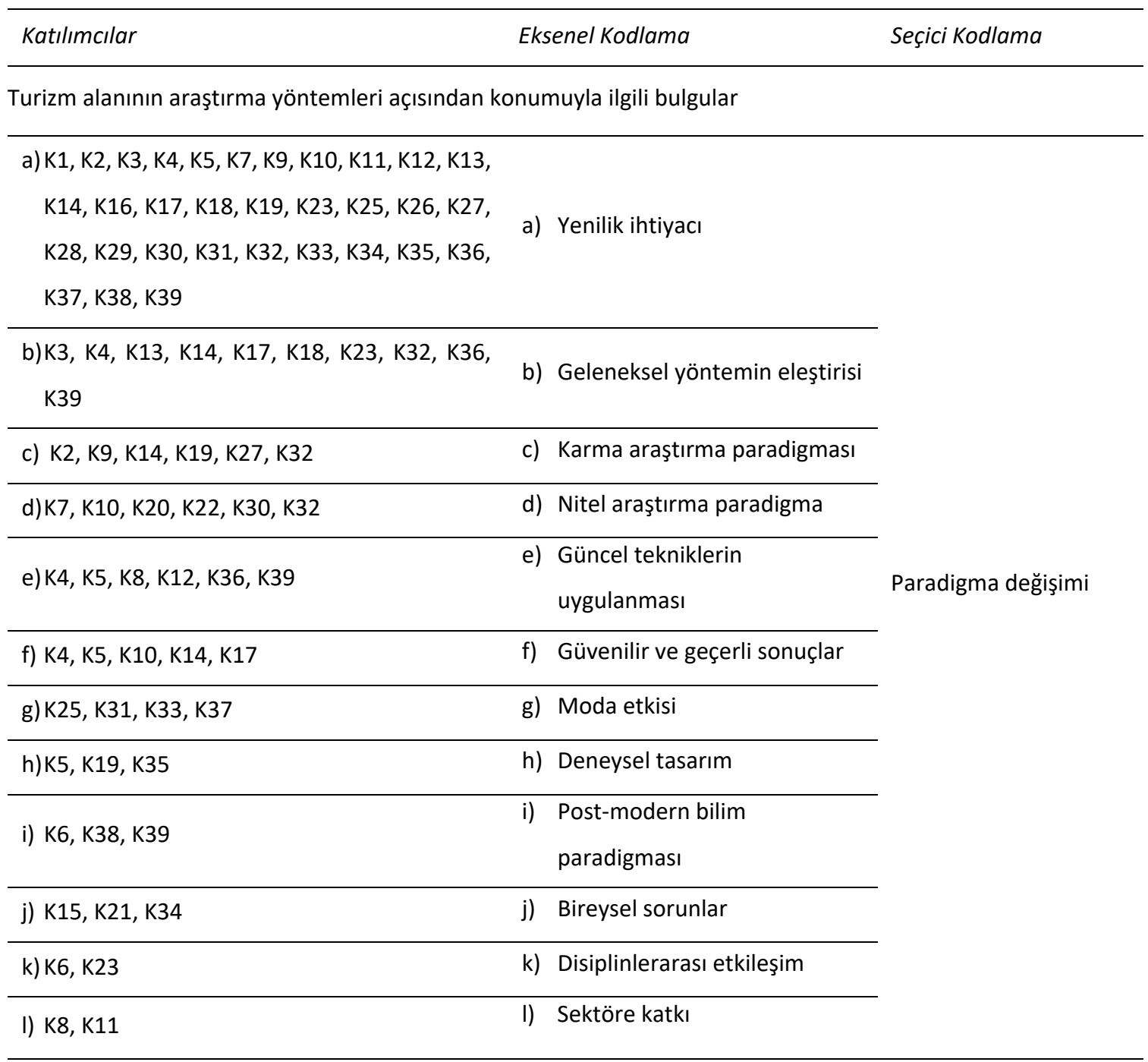

Alanın bilimsel gelişiminde hangi yöntemin daha gerekli/etkili olduğuyla ilgili bulgular
a) K2, K5, K6, K8, K9, K10, K11, K13, K14, K16,
K19, K21, K22, K26, K27, K31, K32, K35, K36, a) Karma yöntem
K37, K38, K39
b) K5, K6, K7, K8, K9, K10, K11, K14, K19, K20,
b) Detaylı bilgiye ulaşma K21, K25, K32, K37, K39
c) K3, K4, K12, K17, K18, K22, K23, K24, K25, K29, K30, K33, K34, K36

\begin{tabular}{ll}
\hline d) $K 2, K 7, K 12, K 14, K 25, K 20, K 32$ & uygunluk \\
\hline e) K7, K15, K20, K22, K25, K28 & d) Nicel yöntemin eleştirisi \\
\hline f) K1, K15 & e) Nitel yöntem \\
\hline
\end{tabular}
Problem-yöntem uyumu 
Tablo 2. Araştırma Sorularına İlişkin Bulgular (Devam)

Araştırma yöntemleri bilgisinin kişisel/akademik gelişim için gerekli görülüp görülmediğiyle ilgili bulgular

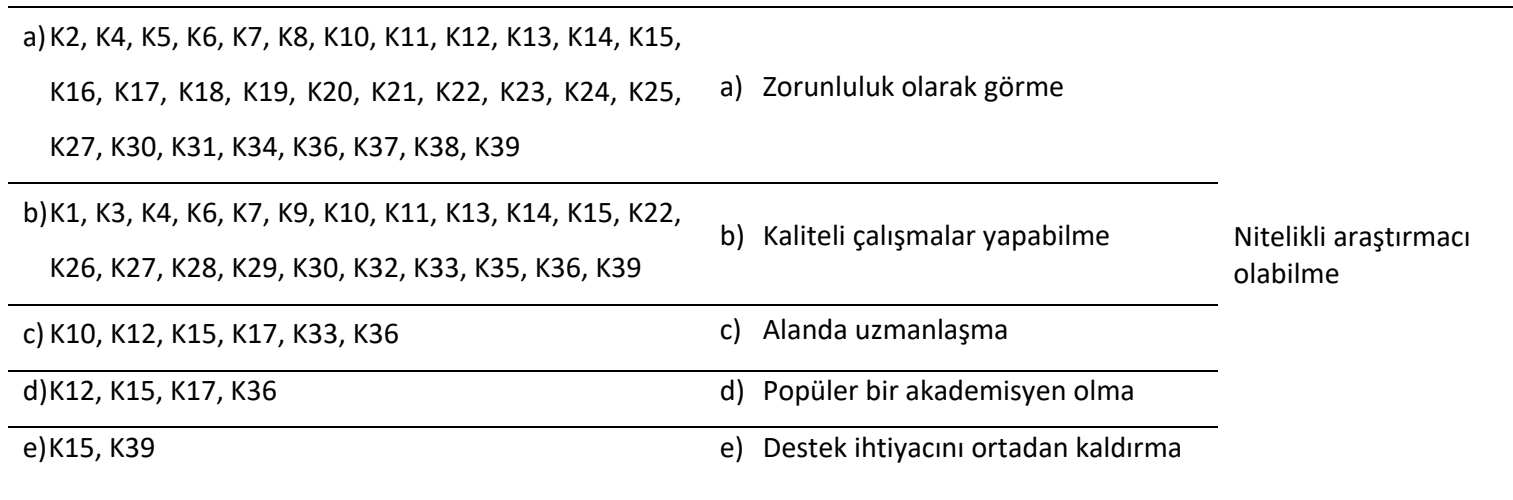

Araştırma yöntemleri konusunda kendini yeterli görüp görmemeyle ilgili bulgular

\begin{tabular}{|c|c|c|c|}
\hline $\begin{array}{l}\text { a) K1, K2, K3, K4, K5, K6, K8, K11, K12, K13, K14, K15, } \\
\text { K16, K20, K21, K24, K26, K27, K30, K33, K35, K37, } \\
\text { K38 }\end{array}$ & a) & Yetersiz görme & \\
\hline $\begin{array}{l}\text { b) K17, K18, K19, K23, K24, K25, K27, K29, K30, K32, } \\
\text { K34, K35, K36, K38 }\end{array}$ & b) & Öğrenme çabası & \\
\hline c) K7, K10, K17, K18, K19, K23, K28, K29, K34, K36, K39 & c) & Kısmen yeterli görme & Gelişime açıklık \\
\hline d) K1, K2, K5, K7, K25, K28, K36, K37 & d) & Yeterliğin mümkün olmaması & \\
\hline e) K6, K8, K12, K13, K26, K39 & & Eğitim sorunu & \\
\hline f) K3, K4, K11, K14, K15 & f) & Tecrübe eksikliği & \\
\hline g) K9, K22, K31, K32 & & Yeterli görme & \\
\hline
\end{tabular}

Veri analizi sürecinde destek alıp almamayla ilgili bulgular

a) K2, K4, K5, K7, K9, K11, K12, K13, K15, K16, K17, K19,

K19, K21, K23, K24, K25, K27, K28, K29, K30, K32, a) Hâkimiyet

K33, K34, K35, K36, K37, K39

\begin{tabular}{ll}
\hline b) K1, K12, K13, K15, K16, K20, K21, K32, K34, K37, K39 & b) Durumsallık \\
\hline c) K10, K14, K15, K22, K31, K32, K34 & c) Tecrübe eksikliği \\
\hline d) K3, K8, K24, K25, K27 & d) Hata yapma korkusu \\
\hline e) K5, K6, K18 & e) Kişisel gelişim \\
\hline f) K4, K37 & f) Farklı bakış açılarından yararlanma
\end{tabular}


Tablo 2. Araştırma Sorularına İliş̧kin Bulgular (Devam)

\begin{tabular}{|c|c|c|c|}
\hline $\begin{array}{l}\text { а) K2, K5, K6, K7, K8, K12, K13, K15, K16, K18, K20, K21, } \\
\text { K22, K24, K25, K26, K27, K28, K29, K30, K32, K33, } \\
\text { K34, K36, K37, K39 }\end{array}$ & a) & Başarısız eğitim & \multirow{10}{*}{ Eğitimde kalite sorunu } \\
\hline $\begin{array}{l}\text { b) K2, K6, K8, K9, K13, K15, K17, K18, K19, K22, K23, } \\
\text { K27, K28, K36, K39 }\end{array}$ & b) & Uzman öğretim elemanı eksikliği & \\
\hline c) K5, K7, K10, K15, K18, K20, K22, K27, K30, K32, K33 & c) & Yetersiz ders içeriği & \\
\hline d) K1, K3, K4, K11, K14, K31, K35 & d) & Başarılı eğitim & \\
\hline e) K30, K33, K34, K36 & e) & Birden fazla ders ihtiyacı & \\
\hline f) $K 27, K 36, K 39$ & f) & Seçmeli ders olarak sunulması & \\
\hline g) K4, K19, K35 & g) & Uzman öğretim elemanı varlığı & \\
\hline h)K7, K30 & h) & Birden fazla dönemde ders ihtiyacı & \\
\hline i) $\mathrm{K} 20, \mathrm{~K} 22$ & i) & Baskın nicel paradigma & \\
\hline j) $\mathrm{K} 24, \mathrm{~K} 25$ & j) & Uzaktan eğitim sorunları & \\
\hline
\end{tabular}

konusunda tam bir yeterliliğin mümkün olamayacağını düşünmektedir. Açık kodlama verilerine göre katılımcıların yöntemsel bilgiyi öğrenme konusunda gösterdikleri çaba ise yüksek düzeydedir. Bu kapsamda, katılımcıların çeşitli nedenlerden dolayı kendilerini yöntem konusunda yeterli bulmadıkları, ancak bu konuda gelişime açık oldukları anlaşılmaktadır [Soru 5].

Bazı katılımcıların çalışmalarında ağırlıklı olarak nicel araştırma yöntemini uyguladığı bazılarının ise çoğunlukla nitel araştırma yönteminden faydalandığı belirlenmiştir. Belirgin bir ağırlık olmadığını, her iki yöntemi de yaygın biçimde kullandığını belirtenler katılımcılar da bulunmaktadır. Bu durumda, nicel veri gerektiren çalışmalar kadar nitel veri gerektiren araştırmaların da tasarlandığı, ikisi arasında belirgin bir eğilimin olmadı ̆̆ı sonucuna ulaşılmıştır. Diğer taraftan, hangi analizlerden faydalanıldığına ilişkin alt soruya çoğu katılımcı yanıt vermemiş ya da uyguladığı analizleri açıkça ifade etmemiştir. Bu nedenle, ağırlıklı olarak yararlanılan analizleri öne çıkaracak nitelikte bir bulguya ulaşılamamıştır [Soru 6]. Bireylerin çevrimiçi olarak katıldıkları araştırmalarda bu gibi durumlarla karşılaşılabilmektedir. Dolayısıyla, soru formunun yüz yüze uygulanmamış olması bu araştırma için bir kısıtlılık olarak değerlendirilmiştir.

Veri analizinin nasıl yürütüldüğüne ilişkin yanıtlar üç aşamalı kodlama yapılarak çözümlenmiştir. Katılımcıların büyük bir çoğunluğunun hâkimiyet ve durumsallık kodlarıyla temsil edilen düşüncelere sahip olduğu görülmektedir. Diğer bir ifadeyle, katılımcılar veri analizini genellikle kendileri yürütmektedir. Bazı katılımcılar araştırmanın bütününe hâkim olmak için bu yolu tercih ettiğini belirtmektedir. Birkaç katılımcı ise kişisel gelişimini desteklemek için veri analizini kendisi yapmaktadır. Diğer taraftan, gerekli durumlarda destek almaktan çekinmediğini belirten katılımcılar da bulunmaktadır. Bu bağlamda, katılımcıların çoğu tecrübe eksikliği ya da hata yapma korkusu nedeniyle destek aldıklarını ifade etmektedir. Eksenel kodlama bulgularından hareketle katılımcıların veri analizi için destek almadıkları, ancak hata riskini ortadan kaldırmak üzere bazı durumlarda desteğe ihtiyaç duydukları anlaşılmaktadır [Soru 7]. 
Son olarak, katılımcıların lisansüstü düzeyde verilen araştırma yöntemleri derslerini başarısız buldukları anlaşılmaktadır. Derslerin yetersiz veya verimsiz bulunmasındaki gerekçeler ise uzman öğretim elemanı eksikliği, lisans düzeyindeki konuların işlenmesi, ileri analiz tekniklerinin öğretilmemesi, teorik bilginin uygulama ile desteklenmemesi, baskın biçimde nicel paradigmanın anlatılması, yöntem derslerinin tek bir dersle sınırlandırılması, sadece bir dönemde verilmesi veya seçmeli ders olarak öğrencilerin tercihine sunulmasıdır. Bu bulgulardan hareketle, turizm alanında lisansüstü düzeyde verilen araştırma yöntemleri derslerinde düşük kalite sorununun bulunduğu ileri sürülebilmektedir [Soru 8].

\section{SONUÇ}

Bu çalışmada, araştırma yöntemleri bilgisinin öneminin tartışılması ve yöntem bilgisinin etkilerine yönelik bir teorik çerçevenin oluşturulması amaçlanmıştır. Bu amaçla, araştırmanın temel problemi olan "araştırma yöntemleri bilgisi neden gereklidir?" sorusu gömülü teori yaklaşımıyla yanıtlanmaya çalışılmış ve araştırma yöntemleri bilgisinin ortaya çıkaracağı etkilerin Şekil 1'deki gibi gerçekleştiği sonucuna ulaşılmıştır. Bu teorik çerçeve, 39 katılımcıdan elde edilen verilerin çözümlenmesi neticesinde ileri sürülmüştür. Araştırmanın bulgular bölümünde eksenel ve seçici kodlamaya ilişkin detaylı bulgulara yer verilmiş olsa da Şekil 1'deki etkileşimleri tanımlama aşamasında açık kodlamadan ulaşılan bulgular da kullanılmıştır. Açık kodlama bulgularının tamamını metne aktarmak mümkün olmadığ 1 için Şekil 1'deki ilişkilerin belirlenmesiyle ilgili bir örnek sunmakta fayda görülmektedir. Örneğin, araştırma yöntemleri bilgisi ile nitelikli yayın arasındaki ilişkiye yönelik K11'in yanıtı: "bilimsel çalışmalarda araştırma metotları belirlenmeden, bilinmeden, iyi şekilde kavranmadan yapılan çalışmalar çok verimli, kapsamlı ve bilimsellikten uzak kalır. İyi bir çalışma için araştırma yöntemlerinin doğru ve gerçekçi bir biçimde ortaya koyulması gerekir".

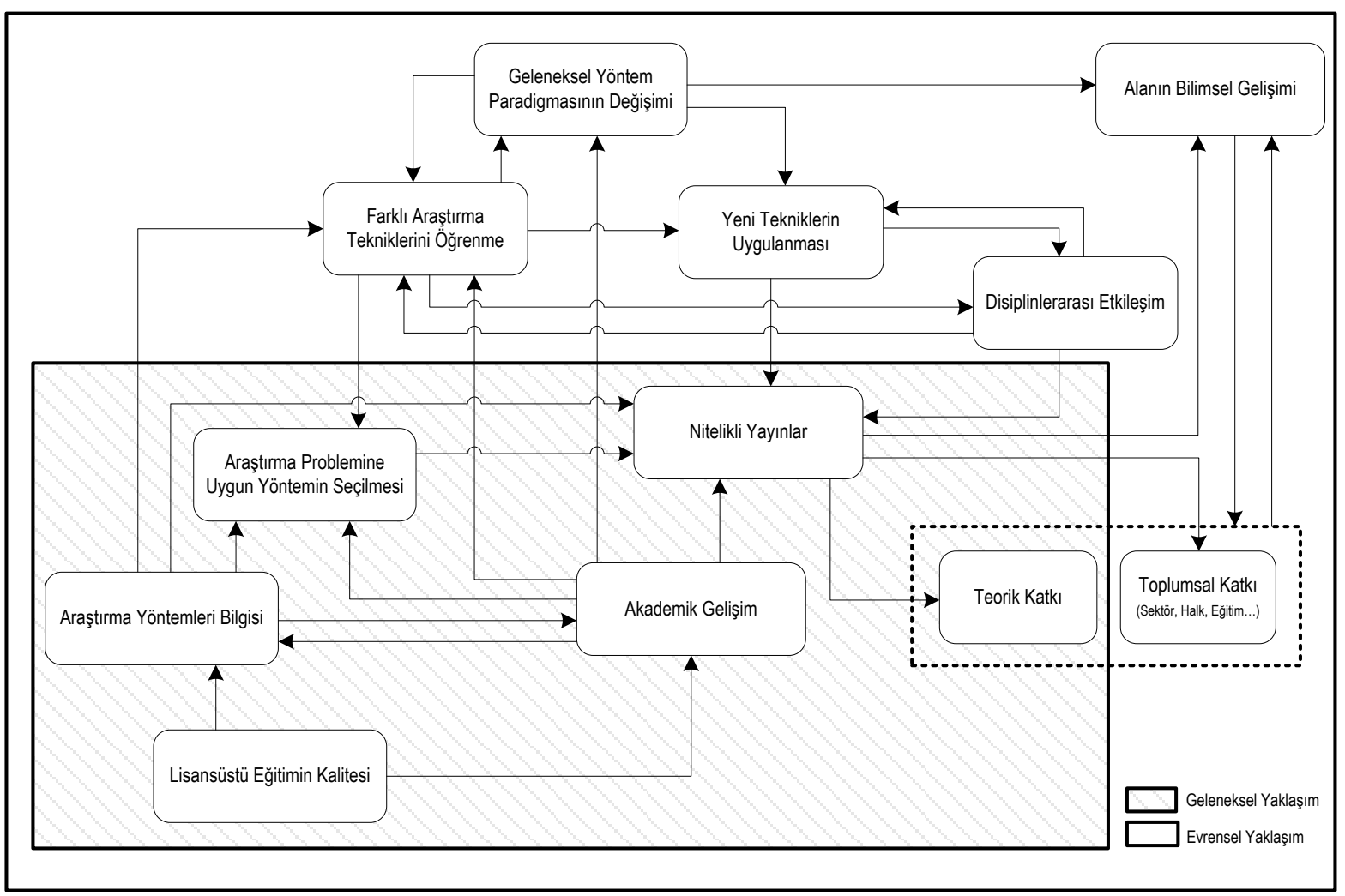

Şekil 1. Araştırma Yöntemleri Bilgisinin Doğrudan ve Dolaylı Etkileri 
Araştırmada ileri sürülen teorik çerçeveye göre, bireylerin araştırma yöntemleri bilgisi, yapılacak çalışmalarda araştırma problemine uygun yöntemleri seçebilme becerilerini güçlendirmektedir (Erdoğan 2013; Kozak 2018). Bu tür bir yetkinlik, araştırmanın tasarımı aşamasında yanlı tutum ve davranışlar yerine probleme özgü yöntemsel yaklaşımın kolaylıkla belirlenebilmesi anlamina gelmektedir. Bu yetkinlik, aynı zamanda, akademik gelişim düzeyiyle de doğrudan ilişkilidir. Diğer bir ifadeyle, araştırmada hangi örneklem tekniğinin kullanılacağı, nicel ya da nitel ve-

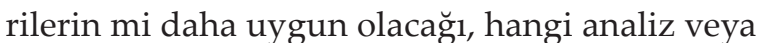
veri çözümleme tekniklerinin uygulanacağı gibi yöntemsel konular araştırmacının yanlılığı yerine araştırma probleminin doğasına göre belirlenebilmektedir. Araştırma yöntemleri bilgisi, akademik gelişim ve araştırma problemine uygun yöntemi belirleyebilme becerisi arasındaki bu güçlü etkileşim, alanında uzmanlaşan bireylerin daha nitelikli çalışmalar yürüterek üst grup yerli ve yabancı dergilerde yayın yapabilmesine yol açmaktadır.

Buraya kadar belirtilen etkileşim, araştırma yöntemleri bilgisinin çıtılarını "geleneksel yaklaşım" olarak adlandırılabilecek bakış içerisinde yorumlayan bireyleri temsil etmektedir. Geleneksel yaklaşıma göre, araştırma yöntemleri bilgisinin yarattığı nihai etki nitelikli yayınların üretilebilmesi vasıtasıyla oluşacak teorik katkıdır. Şekil 1'de alt küme olarak sunulan bu yaklaşım, araştırma yöntemleri konusundaki yetkinliğin bir sonucu olan nitelikli yayınların teorik katkı için yapıldığını kabul etmektedir. Bu yaklaşımı temsil eden bireyler, nitelikli yayınları alan yazına önemli bir katkı yapma, ilk kez çalışılan özgün konuları keşfetme veya kuram geliştirme gibi teorik bir bakış açısıyla değerlendirmektedir. Dolayısıyla, geleneksel yaklaşımı benimseyen bireyler araştırma yöntemleri bilgisinin yaratacağı etkiyi bu çerçeveyle sınırlandırmaktadır. Buna karşın, "evrensel yaklaşım" olarak adland1rılabilecek bakış açısından değerlendirildiğinde, doğrudan ve dolaylı etkilerin daha fazla olduğu söylenebilmektedir.

Şekil 1'de görüldüğü üzere evrensel yaklaşım, geleneksel yaklaşım içindeki tüm etkileşimleri kapsamakta ve araştırma yöntemleri bilgisinin ortaya çıaracağ 1 etkilerin çok daha geniş boyutlara ulaşabildiğini göstermektedir. Bu bağlamda, araştırma yöntemleri bilgisi, geleneksel yaklaşımda belirtilen etkileşimlere ek olarak, bireylerin farklı araştırma tekniklerini öğrenmesini kolaylaştırmakta ya da bunları keşfetme motivasyonunu güçlendirmektedir. Çünkü araştırma yöntemleri konusunda yetkin bireyler, takip ettikleri nitelikli yayınlarda rastladıkları farklı teknikleri daha kolay yorumlayabilmekte ve ek okumalar yapma gerekliliği hissederek söz konusu teknikler hakkında daha fazla bilgi toplamaktadır. Yeni teknikleri öğrenen bireyler hem bunları kendi çalışmalarında uygulayabilecek hem de yenilikçi bir bakış açısı geliştirerek alanlarındaki geleneksel yöntem paradigmasının değişimine etki edebileceklerdir.

Ayrıca, geçen yüzyılın sonlarında başlayan ve içinde bulunduğumuz yüzyıl ile birlikte turizm araştırmalarının disiplinlerarası özelliğine vurgu yapan çalışmaların sayısal anlamda artmaya başladığı görülmektedir (Jafari 1990; Kozak ve Kozak 2016; Tribe ve Xiao 2011). Ardından 2020 yılı başlarında kendisini gösteren pandemi sonrasında, sağlık başta olmak üzere, turizm araştırmalarında bu tür disiplinlerarası iş birliklerine daha fazla gerek olacağı konusunda bazı tartışmalar da başlamış durumdadır (Wen, Wang, Kozak, Liu ve Hou 2021). Bunun için de farklı teknikleri öğrenmek veya bu teknikleri uygulayabilmek için çeşitli disiplinlerden araştırmacılar ile etkileşim kurulması kaçınılmaz olmaktadır. Böylece, disiplinlerarası çalışmalar ortaya çıacak ve bu çalışmaların sayısı düzenli biçimde artacaktır. Disiplinlerarası bu etkileşim, yeni tekniklerin öğrenilmesi ve uygulanması imkânını da güçlendirecektir.

Bu değişimin kendisi ve yarattı̆̆ da ortaya çıkan nitelikli yayınlar ise alanın diğer bilim dalları tarafından tanınmasını, diğer alanlardan daha çok atıf almasını ve bir bilim dalı olarak kabul görmesini yani o alanın bilimsel gelişimini desteklemektedir. Teorik katkının yanında toplumsal katkının da üretilmesi önem arz etmektedir. Turizm yayınlarının pratikte de uygulanabilir bilimsel bilgiler üretmesi ise güçlü -belki 
de turizme özgü- teorilerin ileri sürülebilmesini mümkün kılarak turizmin bilimsel konumunu güçlendirecektir. Nitekim, çok uzun bir süredir birçok uluslararası turizm dergisi, yayımladıkları makalelerin sonuç kısmında uygulamaya ya da topluma dönük çıkarımlara da yer vermektedir.

Bu çalışma, "araştırma yöntemleri bilgisi neden gereklidir?" sorusunu kapsamlı biçimde yanıtlayarak alan yazındaki önemli bir boşluğu doldurmaktadır. Çalışmada, ileri sürülen evrensel yaklaşımın önemi ortaya konularak özellikle genç araştırmacılar için bir vizyon sunulduğuna da inanılmaktadır. Bu bağlamda mevcut çalışma, geleneksel yaklaşımdan dünya ile entegre olmuş evrensel yaklaşıma doğru bir akışın gerekliliğini ortaya koymaktadır. Bununla birlikte çalışmanın bazı sinırlılıkları da bulunmaktadır. Bunlardan ilki veri toplama sürecinde çevrimiçi soru formunun uygulanmasıdır. Katılımciların soruları yazılı olarak yanitlaması daha kısa cevaplara neden olmuş olabilir. Diğer bir sınırlılık ise çalışmanın sadece Türkiye'de yürütülmesidir. Farklı ülkelerden katılımcılar ile yürütülecek bir çalışma alana yönelik daha bütüncül bir çıkarım sunabilir. Son olarak, sadece turizm alanına dönük bir çalışma yerine diğer disiplinlerde de benzer çalışmaların yapılmasıyla sosyal bilimler genelinde genel bir değerlendirmenin ortaya konulması mümkün olacaktır.

\section{KAYNAKÇA}

Acar, D. ve Gül-Yılmaz, E. (2019). Uluslararası Turizm Araştırmalarında Türkiye'nin Yeri, Anatolia: Turizm Araştırmaları Dergisi, 30 (2): 45-57.

Akış-Roney, S. (2011). Bilimsel Araştırma Nedir?, Anatolia: Turizm Araştırmaları Dergisi, 22 (2): 211-215.

Bao, J., Chen, G. ve Jin, X. (2018). China Tourism Research: A Review of Publications from Four Top International Journals, Journal of China Tourism Research, 14 (1): 1-19.

Brennan, N. M. (2019). 100 Research Rules of the Game: How to Make Your Research World Class; How to Successfully Publish in top International Refereed Journals, Accounting Auditing \& Accountability Journal, 32 (2): 691706.

Çıvak, B. ve Sezerel, H. (2018). Araştırma Paradigmaları ve Turizm Yazını, Turizm Akademik Dergisi, 5 (1): 1-14.

Dann, G., Nash, D. ve Pearce, P. (1988). Methodology in Tourism Research, Annals of Tourism Research, 15: 1-28.

Erdoğan, İ. (2001). Sosyal Bilimlerde Pozitivist-Ampirik Akademik Araştırmaların Tasarım ve Yöntem Sorunları, Anatolia: Turizm Araştırmaları Dergisi, 12 (2): 119-134.
Erdoğan, İ. (2013). Sosyal Bilimlerde Araştırma Yöntemleri: Sorunlar ve Çözümler, Anadolu Üniversitesi Sosyal Bilimler Dergisi, 13 (1): 1-12.

Faulkner, B. ve Goeldner, C. R. (1998). Progress in Tourism and Hospitality Research, Journal of Travel Research, 37 (1): 76-80.

Jafari, J. (1990). Research and Scholarship: The Basis of Tourism Education, Journal of Tourism Studies, 1(1): 33-41.

Jones, P. A. ve Philips, D. (2003). What Use is Research Anyway? Industry and Academe's Differing Views, International Journal of Contemporary Hospitality Management, 15 (5): 290-293.

Khan, M. A. (2019). A Systematic Assessment of Gaps between Academic Research and Industry Participation in Hospitality Management Discipline, International Journal of Hospitality Management, 82: 82-90.

Kock, F., Josiassen, A. ve Assaf, A. G. (2019). Scale Development in Tourism Research: Advocating for a New Paradigm, Journal of Travel Research, 58 (7): 1227-1229.

Kozak, M. (2018). Bilimsel Araştırma: Tasarım, Yazım ve Yayım Teknikleri. Ankara: Detay Yayıncılık.

Kozak, M. ve Kozak, N. (2016). Institutionalisation of Tourism Research and Education: From the Early 1900s to 2000s, Journal of Tourism History, 8 (3): 275-299,

Lanke, P. ve Nath, P. (2020). What Have We Learned? 10 Years of Current Issues in Methods and Practice, Current Issues in Tourism, 23 (24): 3016-3024.

Laws, E. ve Scott, N. (2015). Tourism Research: Building from Other Disciplines, Tourism Recreation Research, 40 (1): 48-58.

Nunkoo, R., Hall, C. M. ve Ladsawut, J. (2017). Gender and Choice of Methodology in tourism Social Science Research, Annals of Tourism Research, 63: 207-210.

Nunkoo, R., Ramkissoon, H. ve Gursoy, D. (2013). Use of Structural Equation Modeling in Tourism Research: Past, Present, and Future, Journal of Travel Research, 52 (6): 759-771.

Nunkoo, R., Thelwall, M., Ladsawut, J. ve Goolaup, S. (2020). Three Decades of Tourism Scholarship: Gender, Collaboration and Research Methods, Tourism Management, 78: 104056.

Rangus, M. ve Brumen, B. (2016). Development of Tourism Research, Teorija in Praksa, 53 (4): 929-941.

Rodriguez-Sanchez, I., Williams, A. M. ve Brotons, M. (2019). The Innovation Journey of New-to-Tourism Entrepreneurs, Current Issues in Tourism, 22 (8): 877-904.

Scott, N., Zhang, R., Le, D. ve Moyle, B. (2019). A Review of Eye-Tracking Research in Tourism, Current Issues in Tourism, 22 (10): 1244-1261.

Sop, S. A. (2017). Turizm Alanındaki Araştırma Görevlilerinin Yayın Performansı ve Yayın Yapmaya Yönelik Görüşleri, Turizm Akademik Dergisi, 4 (1): 17-31.

Tribe, J. (1997). The Indiscipline of Tourism, Annals of Tourism Research, 24: 628-657.

Tribe, J. ve Xiao, H. (2011). Development in Tourism Social Science, Annals of Tourism Research, 38 (1): 7-26.

Türkdoğan, O. (1995). Bilimsel Değerlendirme ve Araştırma Metodolojisi. İstanbul: Milli Eğitim Basımevi. 
Vong, F. (2017). Relevance of Academic Research to Hospitality Practitioners, Journal of Hospitality and Tourism Education, 29 (3): 116-128.

Wardle, C. ve Buckley, R. (2014). Tourism Citations in Other Disciplines, Annals of Tourism Research, 46 (3): 163-184.

Wen, J., Wang, W., Kozak, M., Liu, X. ve Hou, H. (2021). Many Brains are Better Than One: The Importance of Interdisciplinary Studies on COVID-19 in and beyond Tou- rism, Tourism Recreation Research, 46(2): 310-313.

Yücel-Toy, B. ve Güneri-Tosunoğlu, N. (2007). Sosyal Bilimler Alanındaki Araştırmalarda Bilimsel Araştırma Süreci, İstatistiksel Teknikler ve Yapılan Hatalar, Ticaret ve Turizm Ĕ̆itim Fakültesi Dergisi, 1: 1-20.

Yüksel, A. (2019). Turizm Akademisinde Yanılsamalar, Seyahat ve Otel İşletmeciliği Dergisi, 16 (2): 340-351.

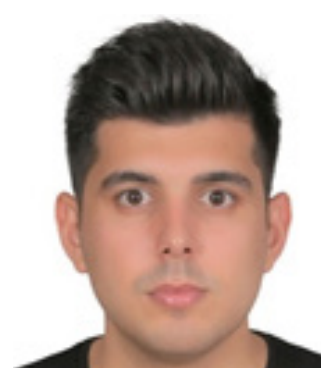

Muğla Sıtkı Koçman Üniversitesi Turizm İşletmeciliği ve Otelcilik Yüksekokulu Konaklama İşletmeciliği Bölümü’nden mezun oldu (2010). Yüksek lisans derecesini aynı üniversitede Turizm Iş̧letmeciliği (2013), doktora derecesini ise Anadolu Üniversitesi'nden Turizm İşletmeciliği alanında aldı (2017). Lisansüstü öğrenim süreci boyunca Muğla Sıtkı Koçman Üniversitesi, Anadolu Üniversitesi ve Burdur Mehmet Akif Ersoy Üniversitesi'nde Araştırma Görevlisi olarak çalışı (2011-2018). Halen Burdur Mehmet Akif Ersoy Üniversitesi Turizm İşletmeciliği ve Otelcilik Yüksekokulu'nda Dr. Öğretim Üyesi olarak görev yapmaktadır. Temel çalışma alanları, turizm pazarlaması, turizmde markalaşma ve tüketici davranışlarıdır.

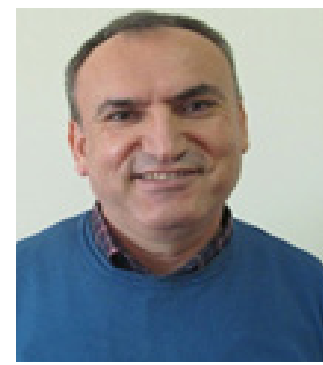

Çukurova Üniversitesi Mersin Turizm İşletmeciliği ve Otelcilik Yüksekokulu'nda Lisans (1991), Dokuz Eylül Üniversitesi Sosyal Bilimler Enstitüsü'nden yüksek lisans (1993) ve Sheffield Hallam Üniversitesi Boş Zaman ve Yiyecek Yönetimi Okulu'ndan doktora (2000) dereceleri aldı. Ulusal ve uluslararası yayımlanmış çok sayıda makaleleri, bildirileri, kitap ve kitap içinde bölümlere sahiptir. Anatolia: An International Journal of Tourism and Hospitality Research Dergisi eş-editörüdür. Halen Dokuz Eylül Üniversitesi Turizm Fakültesi'nde Profesör olarak görev yapmakta olup, uzmanlık alanları arasında tüketici davranışları, pazarlama ve rekabet edebilirlik gelmektedir. 